Max-Planck-Institut für demografische Forschung Max Planck Institute for Demographic Research Doberaner Strasse 114 - D-18057 Rostock · GERMANY

Tel +49 (0) 3812081 - 0; Fax +49 (0) 3812081 - 202; http://www.demogr.mpg.de

MPIDR WORKING PAPER WP 2001-023

AUGUST 2001

\title{
Changing pattern of fertility behaviour in a time of social and economic change: Evidence from Mongolia
}

\author{
Arnstein Aassve (aassve@ demogr.mpg.de) \\ Gereltuya Altankhuyag (altankhuyag@demogr.mpg.de)
}

This working paper has been approved for release by: Francesco C. Billari (billari@ demogr.mpg.de) Head of the Research Group on the Demography of Early Adulthood.

C) Copyright is held by the authors.

Working papers of the Max Planck Institute for Demographic Research receive only limited review. Views or opinions expressed in working papers are attributable to the authors and do not necessarily reflect those of the Institute. 


\title{
Changing pattern of fertility behaviour in a time of social and economic change: Evidence from Mongolia
}

\section{Arnstein Aassve and Gereltuya Altankhuyag}

Max Planck Institute for Demographic Research

\begin{abstract}
In 1989, after a long period of socialist rule, Mongolia initiated a democratisation process of its political system together with a transition towards a market economy. This paper examines how changes in socio-economic conditions in Mongolia have affected fertility patterns in recent times. It also provides an outline of changes that have taken place in terms of pro-natalist policies. The study is based on data from the Reproductive Health Survey of Mongolia (RHSM) conducted in 1998. In terms of economic activity we find an inverse, although weak, relationship for older cohorts. This is in strong contrast to the young cohort, for which the economic downturn has had a strongly depressing effect on fertility. We also find important effects of micro level variables, including education and housing. Our findings suggest that the fertility decline observed for the older cohorts are very much part of the first demographic transition, in which the collapse of pro-natalist policies has been influential.
\end{abstract}




\section{Introduction}

This paper examines how changes in socio-economic conditions in Mongolia have affected marriage and fertility patterns in recent times. Relatively little is known about these patterns in Mongolia, a feature largely due to lack of adequate data sources. Neupert 1996, using aggregate measures, provides most of the demographic analysis known so far. In the present study we use new micro level data to investigate fertility and marriage behaviour. The information is drawn from the Reproductive Health Survey of Mongolia (RHSM) which was conducted in 1998. This data set provides detailed information on all birth parities as well as on marriage, together with a range of other background characteristics.

The motivation for this paper is twofold. First we aim to provide a detailed micro level analysis of marriage and birth parities. This has never before been undertaken for Mongolia. Second, and equally important, is to examine how recent changes in economic prosperity has affected the Mongolian people's family formation behaviour. In 1989, after a long period of socialist rule, Mongolia initiated a democratisation process of its political system together with a transition towards a market economy. Currently, the country is experiencing a deep economic crisis, characterised by a substantial decline in the standard of living and increased levels of poverty and unemployment. The change from a centrally controlled economy has also had strong political implications on family planning and fertility. Up until 1989 the Mongolia had a strong pro-natalist policy with generous benefits for having children and strong policies towards reducing child mortality. These policies have more or less been 
abolished in the new system of the nineties. It is clear that these changes have had strong implications on fertility and family formation in general, and they certainly warrant investigation.

\section{Background}

\subsection{Mongolia's economic and political situation}

Mongolia covers a territory of 1.565 thousand square kilometres where the main geographical feature is the steppe. The land is particularly apt for extensive animal husbandry, which has been precisely the determinant of the Mongolian way of life and main economic activity from ancient times until the present. Thus nomadic pastoralism has been, and still is, the traditional and dominant way of living (Neupert, 1996:8). The present livestock population is over 30 million, which is more than twelve times the human population. At present, the population of Mongolia is 2.4 million and its population density, at 1.52 persons per square kilometre, is one of the lowest in the world. A third of the total population live in Ulaanbaatar, the capital city. The share of urban and rural population is 57 and 43 percent, respectively. The population is very homogeneous in ethnic composition. About 95 percent are of Mongol-speaking origin.

Mongolia's geographical location, sandwiched between the Russian Federation and the People's Republic of China, has dramatically determined its political and economic climate in recent decades. Its links with the former USSR has been particularly influential and up until 1989 Mongolia developed an extreme dependence in terms of imports and on financial assistance from the former Soviet states. Imports reached 58 per cent of GDP, almost 80 per cent of which came from the USSR. 
During this period the economy was stable and the country achieved enormous progress in terms of social development. A more or less complete network of social services with a wide range of social security payments were implemented. There were also social assistance benefits such as maternity payment, child benefits, family allowances, and even honours for having many children (National Statistical Office of Mogolia 1994:5). Education and medical care were generally free and of good quality. In the same period the average annual growth rate of GDP was 6.1 and 5.7 per cent in 1970s and 1980s respectively. There was also a general shift towards a more industrial and modern society. In 1940, the industry accounted for only 7 percent of the national income while in 1989 its contribution was 32.7 per cent. The share of agriculture, including animal husbandry, fell from 76.1 to 15.5 per cent during the same period.

Since 1989 the country has witnessed dramatic political and economic changes. The democratisation process of its political system and the move towards a market economy was established formally in the new constitution of Mongolia in 1992. Mongolia has been one of the quickest to adopt and implement economic reforms. This rapid transformation has been, and still is, a painful experience for the Mongolian people. In particular, unemployment and poverty has increased dramatically. The 1998 Living Standard Measurement Survey (LSMS) suggests that the national unemployment rate is as high as 19 percent and that around 36 per cent of the total population live in poverty (Government of Mongolia and UNDP 2000). Furthermore, it is estimated that between 1990 and 1993 real wages fell by one-fifth in industry and by one third in agriculture and services. This is of course a consequence of the collapsed economy. Since 1989 industrial output declined sharply. 
This was accompanied by a sharp increase in the inflation rate, which peaked at 326 percent in 1993. There has also been persistent budget deficit due to insufficient tax revenues. For the majority of people the early transition years were the most difficult and particularly hard for female-headed families and families with many children. With the new system, childcare and schooling are no longer free and parents are often unable to meet this financial burden. At the same time family benefits have been reduced, dramatically affecting the financial incentives to bear children. Couples are forced to rely on their own income and any wealth to feed and raise their children. These societal upheavals must have been influential in women's childbearing behaviour.

At the beginning of the new millennium there are some positive signs of revival in the Mongolian society. The inflation rate has fallen sharply since its peak in 1993 and the GDP growth figures are again positive, although do not reach the levels experienced before 1989. (See Figure 1 for a time series of the GDP growth rate.) There has also been positive growth in animal husbandry, where privatisation has encouraged a rapid expansion of herds ${ }^{1}$. Economic reforms seem slowly to take effect. After 1995, and after a series of policy interventions, some of the lost ground has been recovered. By 1998 the overall human development index had virtually recovered to the 1990 level. The real GDP per capita adjusted for purchasing power increased by 2.6 percent in 1998 and life expectancy was at 65 years. An important contribution to this improvement has been a reduction in infant and maternal mortality. Furthermore, the school enrolment rate for children aged 8 to 15 increased somewhat (from 84 per cent in 1994 to a level of 87 percent in 1998). 


\subsection{Fertility in Mongolia: Context and trends}

The pattern of fertility decline in Mongolia during 1960-1990 is similar to that in many other countries, including Russia and the former socialist countries in Central and East Europe. However, the patterns are certainly not synchronised. For instance, Mongolia experienced a drop in the TFR from 6 to 3 in a period of 19 years, whereas similar drops in the TFR took about 10 years in China and 23 years in Russia. Furthermore, the decline in the TFR in Mongolia lags the Russian TFR rates by about 10 to 15 years. Between the years 1960 and 1968 the TFR in Mongolia stayed stable at a level of 8 children, whereas it fell substantially in Russia (Avdeev, 2001:5) ${ }^{2}$. The differences between the two countries are to a large extent due to differences in historical events and in policy measures. Figure 2 shows how the TFR has declined in Mongolia between 1960 and 1998. A very noticeable feature of this picture is the strong difference between the TFR today and that of the 1960s and mid 1970s. The drop is from a level of 8 children down to less than 3 in a period of 20 years. The slide is particularly marked from about 1975 onwards, which is consistent with a moderate relaxation of the restrictive pro-natalist policy. The pro-natalist policy had several components. For instance, women with more than four children were awarded medals of honour, additional child allowances and subsidised holiday leave, and were given earlier retirement (50 years of age). Generous maternity-leave also applied and women were guaranteed to return to their original job after having a child. In addition

\footnotetext{
${ }_{1}$ Part of this growth is reflects a sectoral shift from industry to agriculture. Between 1990 and 1998 the share of industry in GDP fell from 35.6 percent to 24.1 percent, while agriculture grew from 15.2 percent to 32.8 percent (Human Development Report Mongolia 2000:29)

${ }^{2}$ There was a notable surge in the TFR in Russia during the 1980s. This was mainly a result of governmental interventions through implementation of a series of social policy measures (Zakharov and Ivanova 1996:6). This temporary rise in fertility is absent from the development experienced in Mongolia.
} 
special taxes were imposed on unmarried and childless couples. Also import, distribution, and use of modern contraceptives were prohibited, and strict regulation was imposed on abortion and sterilisation. In 1976 a first attempt was made to provide family planning, and the IUD became legal in cases were pregnancies were not recommended, either because of the woman's health or age, or because the woman had experienced more than five pregnancies. In 1988, a more significant policy change took place. The existing family planning services were expanded, and modifications were introduced in the abortion law. At the end of 1989, abortion was fully legalised and all restrictions on the use, distribution and import of contraceptives removed (Neupert 1996). The graph shows that fertility decline has been strong during the period in which the pro-natalist policies were relaxed ${ }^{3}$.

If we take the GDP as a measure of economic activity and general prosperity, then our graph (figure 2) shows a clear inverse association regarding fertility until $1989^{4}$. After this time the association is clearly positive. About two years after the transition started the decline is clearly intensified and from 1992 to 1993 there is a drop from 3.5 to 2.6. The positive association between GDP and TFR is less marked after 1994. The fact that we have only a few data points prevents us from making strong predictions about this relationship for the future ${ }^{5}$. The sharp decline in fertility during the 1990s is of course not a unique feature of Mongolia. All of the Eastern and Central European countries experienced a similar rapid decline (Kohler \& Kohler 2001). There are however, conflicting views about why this happened. A common explanation is based on the economic crisis. According to this theory lower income, higher unemployment

\footnotetext{
${ }^{3}$ Some pro-natalist policy measures are still in place. Cash benefits are still provided for large families and maternity leave is also provided at all parities.

4 The national currency of Mongolia is the tugrik and in Figure 2 GDP values are given in thousand tugriks. In 1998 the exchange rate was approximately 1020 tugriks pr US dollar.
} 
and worsened job security make individuals postpone childbearing. Others take the view that the recent decline is a reflection of a second demographic transition ${ }^{6}$, in which the former socialist countries are in a process of convergence towards family patterns common in the West. Both hypotheses are of course consistent with the observed general pattern of fertility decline ${ }^{7}$.

\section{Data, methodology and covariates}

In this study we use individual level birth histories to analyse the timing of women's first, second, and third birth orders. The data, which contains information on women's marriage and birth events, were derived from the 1998 Reproductive Health Survey of Mongolia (RHSM). The RHSM was conducted using a two-stage sampling method, with an equal probability of selecting the households. A total of 6,005 households, corresponding to 1.13 percent of the total number of households, were selected and 240 clusters or primary sampling units with 25 households in each, were constructed. A total number of 7535 women between the ages of 15 and 49, who stayed in the household's dwelling the night prior to the date of survey, were interviewed. In addition, six husbands from each cluster, or 1,557 husbands in total, were interviewed. Data were collected using face-to-face interviews.

In our sample 5609 first births, 4382 second births and 2999 third births were recorded. We divided the sample in two according to date of birth of the respondent and conducted estimation in each part separately. The first group consists of women

\footnotetext{
${ }^{5}$ Neupert (1996) provides a detailed analysis of population trends of Mongolia.

${ }^{6}$ See van de Kaa (1987)

7 See Kohler and Kohler (2001) for a more detailed analysis and an attempt to identify the underlying mechanism of the observed fertility decline in Russia in the 1990s.
} 
born between 1949 and 1973 and the second group was born between 1974 and 1983. The latter group represents women who started their childbearing just before the economic transition started in 1989. It is therefore of particular interest to see how their childbearing behaviour is different from the first group. The group of older women can be thought of as representative of reproduction behaviour in the traditional socialist era. Given the pattern of GDP and TFR in Figure 2, we expect a quite different impact for the two groups of women. A hazard regression model using time since age 12 as the duration variable estimates the determinants of first birth. For second births we use the duration from first birth, and similarly we use the duration from the second birth event for third births. (See figure 3 for illustration.) We use a simple piece-wise constant exponential model. This is fully parametric yet simple and flexible in terms of the shape of the baseline hazard, thus allowing for a range of duration dependence patterns. Estimation was performed separately for the three birth events for each of the two cohort groups of women. Third birth intensities for the youngest cohort were not estimated due to the small sample size. We also estimated intensities of marriage using age 12 as our time variable.

Figure 3: Framework of the study.

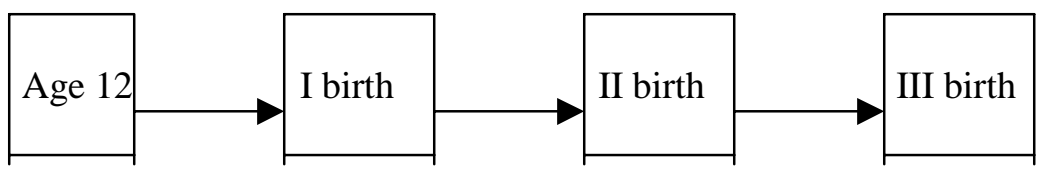

Economic activity and prosperity determines to a large extent individuals employment opportunities and income level. Thus, in periods with low economic activity we expect individuals to have a lower income as well as greater uncertainty with regard 
to their future employment. Assuming that income and prosperity is positively linked with fertility we expect an economic downturn to have a depressing effect on women's fertility behaviour. The GDP variable used here is of course only an approximate indicator of how individuals perceive their economic situation. It can be argued that other macro variables better capture individuals' economic situation. Obvious candidates are regional unemployment rates or poverty rates. However, for Mongolia these figures are generally non-existent or unreliable. Our GDP variable is given in 1995 constant prices and de-trended ${ }^{8}$. The values have been assigned to each individual in the sample, taking into account each respondent's reproductive age, starting from age $12^{9}$.

The RHSM includes information on educational attainment of all respondents. We have used this to reproduce enrolment status and educational attainment as time varying variables, thus separating the effect of currently being enrolled from that of the level attained. Education in Mongolia is split naturally into four levels. These are (i) the primary level, normally completed at age 12 , (ii) $8^{\text {th }}$ grade of schooling (age 16), (iii) secondary school (age 18), and (iv) higher education, normally completed at age 23. Everybody in our sample has completed primary school. We generally expect being in education to strongly reduce fertility. As for the educational levels we expect a negative gradient in so far as the extra opportunity cost of having children outweighs the extra income generated from having a higher education. The data also provide information about whether the individuals owned their own livestock. Given that animal husbandry is the main source of livelihood we might expect this to be an

8 This is implemented by running an Ordinary Least Squares regression of GDP on a constant term and time. The resulting residuals represent the de-trended GDP values and used as a covariate. 
approximation to individuals' wealth. Individuals who live in rural areas and do not own their own livestock are normally poor. There are two important problems with this measure. First, the variable is dichotomous, so it does not capture the amount of livestock individuals own. The size of the livestock herd is of course a much closer approximation of individuals' income and wealth. Second, private ownership of livestock only became prevalent after 1989 when the economic reform started. Consequently the variable is only relevant for the youngest cohort. Our data shows that a significant proportion of those who live in urban areas also own livestock. Therefore, in order to identify any possible differences in behaviour of these groups, we included an interaction term between (i) the respondents' place of residence and (ii) whether they own livestock. We have distinguished three types of housing. These are "ger", private house and apartment. Ger is the traditional dwelling unit suitable for the nomadic economy in Mongolia; the census of 2000 showed that about half of the population live in this form of housing. The main subsistence of livelihood of newly married couples in rural areas is livestock that are given to them as inheritance from both parents. The pastoral or nomadic economy is of course dominating in rural areas, and the majority of families in rural areas consequently prefer to live in ger. Ger is extensively used in rural areas, although not exclusively. In our sample the number of respondents who lived in rural areas but not in ger is 938, whereas the number of individuals living in rural areas in ger is 2656.

${ }^{9}$ For instance, a woman aged 12 in 1975 is assigned the real GDP per capita for that year. In 1976 she is assigned the corresponding value in 1976, and so forth, until the first birth event occurs. The same procedure is 


\section{Findings}

Table 1 contains the results for the first-birth intensities. The results are reported separately for the old cohorts (born between 1949 and 1973) and the young cohort (born between 1974 and 1983). For the old cohorts we are able to identify additional cohort effects. There is a significant delay of the first birth event among younger cohorts. We expect of course delayed entry into childbearing to have an inverse association with completed fertility ${ }^{10}$ so these negative coefficients are consistent with the overall decline in the TFR over the period, as shown in figure 2. For both cohort groups we find a positive relationship between economic prosperity and timing of first birth. However, the relationship for the older cohorts is not statistically significant, and indicates that other forces than economic prosperity and growth were important during the period of socialist rule. It seems plausible that the relaxation of the pronatalist policies, captured by the cohort dummy variables, has been more influential. For the young cohort, on the other hand, the economic downturn has worked as an effective break on women's childbearing. An important implication of this result, assuming the relationship will persist, is that any future improvements in economic activity might help to increase fertility levels. Other variables are also important. As expected, being enrolled at school significantly delayed first birth, especially for the old cohorts. Table 1 also shows that there is a delaying effect associated with educational attainment, and the effect is particularly strong among those undertaking higher education. Compared to women with $8^{\text {th }}$ grade of schooling, women with a secondary education in these cohorts had a 9 percent lower first-birth intensity and for women with higher education the reduction is about one-third. The effect of 
educational attainment is not too dissimilar for the young cohort, but here the coefficients are not well determined. Our estimates suggest that women who live in rural areas tend to start childbearing at a considerably younger age than women in urban areas. For the young cohort we find no strong impact of owning livestock, nor do we find any joint impact of living in a rural area and owning livestock. In sum we find the cohorts, school enrolment and educational attainment to be the main factors affecting the timing of first birth for older women, while economic conditions, school attainment and rural residence are the key factors among younger women.

Table 2 contains the results for the second birth transition. They indicate a clear inverse relationship with respect to economic prosperity for the older cohorts. This is in contrast to the timing of first birth, and suggests that although economic activity had little effect on the timing of women's childbearing career, it has had a significant timing effect of the higher birth parities. However, the impact of economic activity during the socialist period is not large compared to the younger cohort, for which the coefficient is positive and considerably larger in magnitude. Again it supports the argument that other forces than economic prosperity has been important in driving the fertility decline during the period of socialist rule. The individual level variables are again important. The effect of enrolment and educational attainment is quite different for the cohort groups. During the socialist period we find the effect of enrolment to have a strong delaying effect, whereas there is no strong effect for the younger cohort. The delaying effect associated with the attained level is generally stronger for the older cohorts and for the younger cohort only higher education has a significant effect. Women in rural areas have second birth at younger ages, and this is the case 
for both the old and the young cohort. There are now significant effects for the different housing arrangements. The housing arrangement can be seen as an approximation for the main occupation of the family, as well as their relative wealth. Those who live in ger generally have a nomadic lifestyle where the main activity is livestock breeding. Women who live in houses or apartments often have jobs that are less compatible with family life. Our results suggest that women who live the traditional way of life have second birth at a considerable younger age. The interaction term between housing arrangement and residence captures whether there is a difference for those who live in rural areas but do not live in ger. For the old cohort there is a weak delaying effect, whereas for the young cohort the effect is not generally significant. The second interaction term between rural residence and ownership of livestock is applied to the young cohort. Again the coefficient is not generally significant and overall the interactions suggest that there are no large differences in timing of second birth among the different groups within rural areas. Overall we find that the effect of economic activity on timing of second birth is significant for both cohorts, but its impact is weak during the period of socialist rule. It is clear that for the young cohort, the downturn in the economy had a much stronger effect in terms of having a second birth. We also find important differences for the different types of housing.

In Table 3 we present the results for the third birth transition. Due to the low number of third births among the young cohort, estimation was only done for the older cohorts. The results are quite similar to that of second birth. In terms of economic prosperity we see that the effect is now slightly stronger. Still the coefficient is not strong compared to what was found for the young cohort of the lower parities. School 
enrolment as well as educational level has strong delaying impacts and women in rural areas have a higher relative risk of third birth. As for the different housing arrangements, we find similar effects to that of second birth. Thus, women living in ger and therefore living a more traditional way of life, have a higher risk of third birth. The relative risk of older women living in private houses in urban areas is reduced by 5 percent in comparison to women living in urban area and in ger.

We have also estimated the transition to first marriage for all women from the age of 12 (Table 4). Preliminary analysis ${ }^{11}$ (Kaplan Meier estimation) indicates that once women are married first birth follows immediately, which is a consistent finding over time and cohorts. Consequently, economic and social factors have very similar effect on the timing of marriage, compared to that of timing of first birth. Table 4 shows that women in the younger cohorts postpone first marriage significantly. The economic activity level has a positive association with the timing to first marriage for the young cohort, as it was observed for the first birth event. However, the parameter is now larger and has a higher level of significance. Both school enrolment and school attainment have an inverse relationship with the timing to marriage for the old cohort group. Women in the young cohort group delay marriage while enrolled at school too, but marriage is accelerated with educational attainment. Place of residence, i.e. urban vs. rural, does not have any large impact on timing of marriage. Women not living in ger marry at an earlier age, but as we have seen from table 1 this is not associated with any acceleration in timing of first birth. Overall, therefore, women who live the traditional nomadic way marry later but have a higher fertility rate once married. The significance of the interaction between rural residence and living in ger reinforces this

\footnotetext{
11 These results are not reported here, but are available from the authors on request.
} 
result, since women living in rural areas, but not the traditional nomadic lifestyle, are considerably less likely to marry.

\section{Concluding remarks}

Since 1975, there has been a long-run fertility decline in Mongolia, a feature which should be seen as an element of the First Demographic transition. Our findings, using a new micro level data set, suggest that during this period the level of economic prosperity did not have a strong causal impact on fertility. It seems more likely that a large part of this fertility decline was driven by the collapse of pro-natalist policies. With the collapse of the socialist system and the consequent economic crisis in the 1990s, our findings suggest that economic activity has become a driving force of fertility decline. Thus, the fall in income levels, increased uncertainty in terms of job prospects, and the disruption of public transfers and support, has certainly had an important effect on women's fertility behaviour. However, the effect of relaxing the pro-natalist policy should not be under estimated, even during the 1990s. The most important change, i.e. legalisation of abortion and contraceptive use, took place in 1988, which of course almost coincide with the economic upheavals just after it. Our data is simply not rich enough to identify the effect of these policy changes, from that caused by the economic crisis. More detailed information is needed in order to identify the relevant mechanism driving the fertility decline in this period. Nevertheless, our study has provided new insight into the demographic patterns of a country which never before has been studied at the micro level. Our findings show that woman's education and housing arrangements are particularly important factors affecting the timing of births, as well as marriage. These results indicate an important 
role of income and lifestyle. Thus, women living in rural areas and living the traditional nomadic lifestyle have higher fertility. It is possible that these women have been less exposed to the reforms taken place regarding abortion and contraceptive use. Women in urban areas, with generally higher income levels and possibly having jobs that are less compatible with childbearing, have considerable lower fertility. Of course women in urban areas have better access to family planning services, which seems to play an important role. 
(Source: Mongolian Statistical Yearbook, 1999)

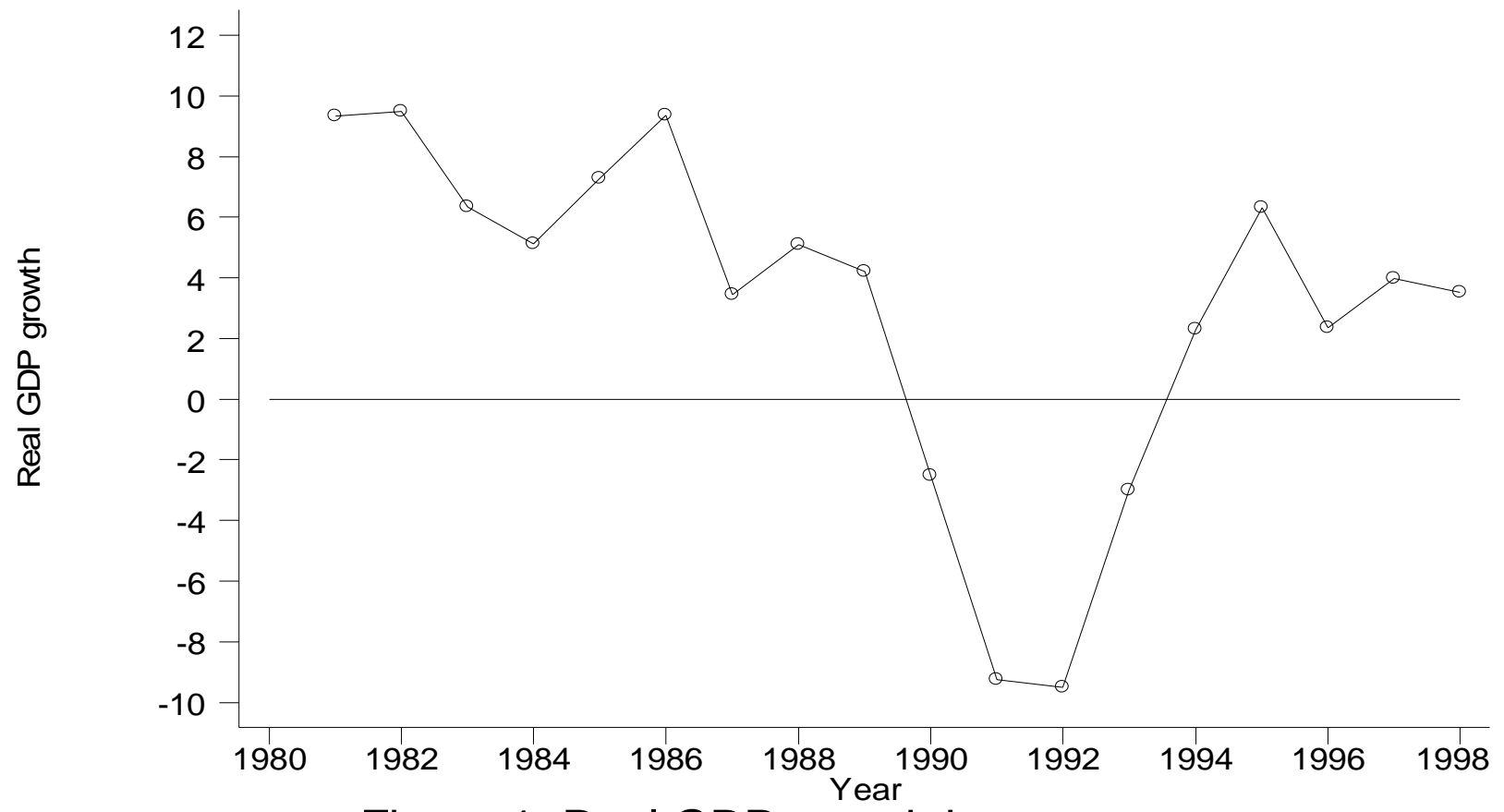

Figure 1: Real GDP growth in percent. 


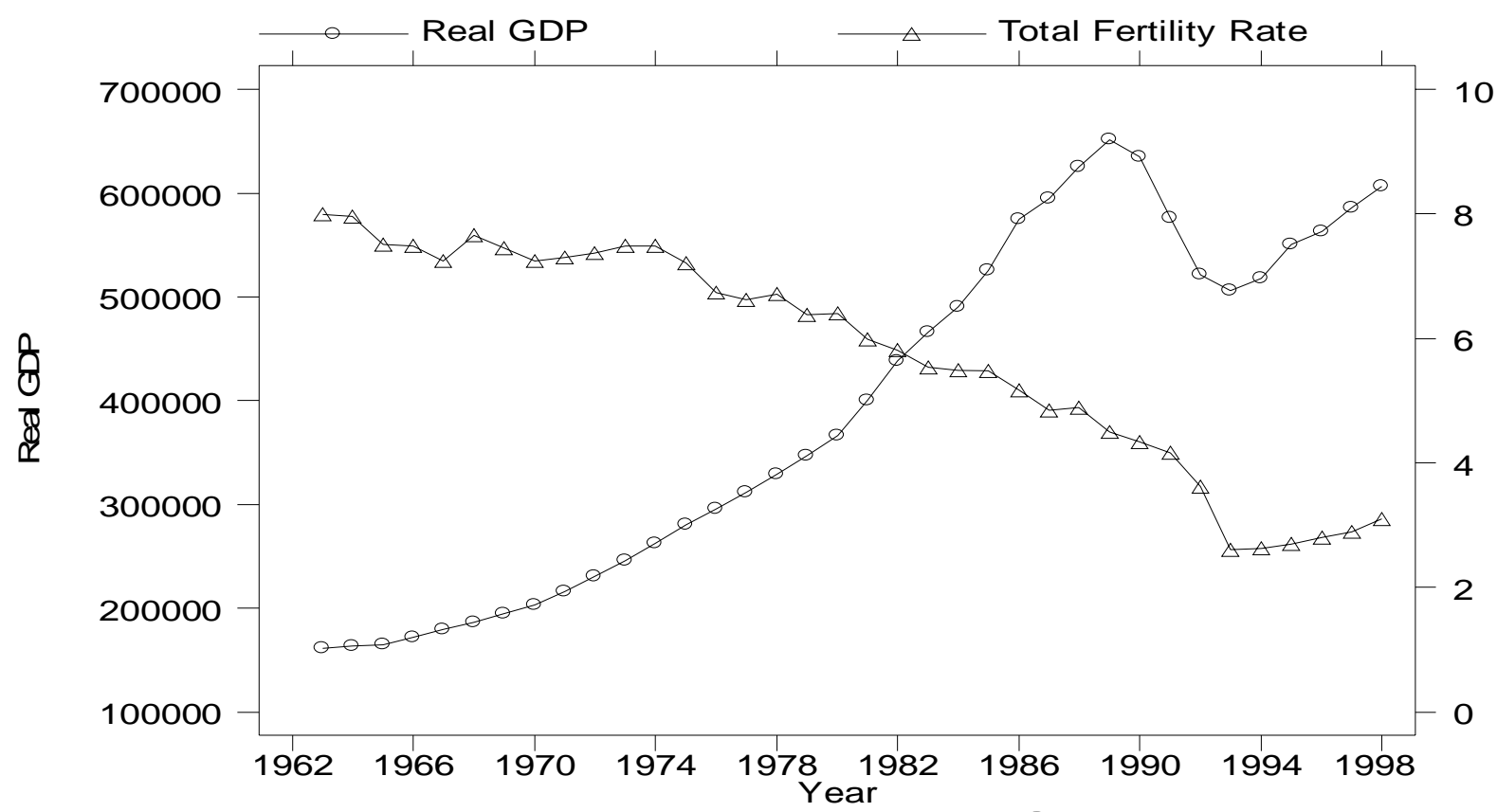

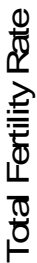

Figure 2: Time series of Real GDP and TFR 
Table 1: Maximum-likelihood estimates, first birth event.

\begin{tabular}{|c|c|c|c|c|c|c|}
\hline \multirow{2}{*}{ Covariates } & \multicolumn{3}{|c|}{ Old cohorts } & \multicolumn{3}{|c|}{ Young cohort } \\
\hline & Coef. & Rel. risk & t-statistics & Coef. & Rel. risk & t-statistics \\
\hline \multicolumn{7}{|l|}{ Reference = Cohort 1949-1958 } \\
\hline Cohort 1959-1968 & -0.274 & 0.760 & $-5.761 * *$ & - & - & - \\
\hline Cohort 1969-1973 & -0.204 & 0.816 & $-5.478 * *$ & - & - & - \\
\hline GDP per capita & 0.001 & 1.001 & 1.193 & 0.005 & 1.005 & 2.163 * \\
\hline School enrolment & -3.568 & 0.028 & -20.636 ** & -3.054 & 0.047 & $-7.188 * *$ \\
\hline \multicolumn{7}{|l|}{ Reference $=8$ th grade } \\
\hline Secondary education & -0.094 & 0.910 & $-2.559 *$ & 0.097 & 1.102 & 1.300 \\
\hline Professional/higher education & -0.409 & 0.665 & -6.221 ** & -0.514 & 0.598 & -1.126 \\
\hline \multicolumn{7}{|l|}{ Reference = Have livestock } \\
\hline Do not have livestock & - & - & - & -0.100 & 0.905 & -0.723 \\
\hline \multicolumn{7}{|l|}{ Reference = Urban } \\
\hline Rural & 0.062 & 1.064 & 1.262 & 0.401 & 1.493 & 2.233 * \\
\hline \multicolumn{7}{|l|}{ Reference $=$ Ger } \\
\hline Private house & 0.032 & 1.033 & 0.583 & -0.102 & 0.903 & -0.664 \\
\hline Apartment & 0.023 & 1.023 & 0.429 & 0.069 & 1.072 & 0.472 \\
\hline Rural $x$ having livestock & - & - & - & -0.141 & 1.300 & -0.680 \\
\hline Rural x ger & 0.072 & 1.143 & 1.019 & 0.320 & 2.056 & 1.661 \\
\hline Number of births & 4723 & - & - & 886 & - & - \\
\hline -Log-likelihood & 22575 & - & - & 4624 & - & - \\
\hline
\end{tabular}


Table 2: Maximum-likelihood estimates, second birth event

\begin{tabular}{|c|c|c|c|c|c|c|}
\hline \multirow[t]{2}{*}{ Covariates } & \multicolumn{3}{|c|}{ Old cohorts } & \multicolumn{3}{|c|}{ Young cohort } \\
\hline & Coef. & Rel. risk & t-statistics & Coef. & Rel. risk & t-statistics \\
\hline \multicolumn{7}{|l|}{ Reference = Cohort 1949-1958 } \\
\hline Cohort 1959-1968 & -0.207 & 0.813 & $-4.460 * *$ & - & - & - \\
\hline Cohort 1969-1973 & -0.232 & 0.793 & $-5.331 * *$ & - & - & - \\
\hline GDP per capita & -0.006 & 0.994 & -7.596 ** & 0.048 & 1.049 & 13.916 ** \\
\hline $\begin{array}{l}\text { School enrolment } \\
\text { Reference }=8 \text { th grade }\end{array}$ & -3.804 & 0.022 & -13.140 ** & 0.016 & 1.016 & 0.068 \\
\hline Secondary education & -2.027 & 0.132 & $-14.703^{* *}$ & -0.099 & 0.906 & -0.417 \\
\hline $\begin{array}{l}\text { Professional/higher education } \\
\text { Reference = Having livestock }\end{array}$ & -3.440 & 0.032 & $-11.842 * *$ & -3.908 & 0.020 & -3.798 ** \\
\hline \multicolumn{6}{|l|}{ Reference = Urban } & 0.478 \\
\hline \multicolumn{7}{|l|}{ Reference $=$ Ger } \\
\hline Private house & -0.142 & 0.868 & $-2.423 *$ & -0.317 & 0.728 & -0.985 \\
\hline Apartment & -0.342 & 0.710 & $-5.931^{* *}$ & -0.556 & 0.573 & -1.709 \\
\hline Rural x having livestock & - & - & - & 0.398 & 2.102 & 0.892 \\
\hline Rural x ger & -0.139 & 1.320 & -1.865 & 0.341 & 1.985 & 0.877 \\
\hline Number of births & 4118 & - & - & 264 & - & - \\
\hline -Log-likelihood & 18616 & - & - & 1310 & - & - \\
\hline
\end{tabular}


Table 3: Maximum-likelihood estimates, third birth event.

\begin{tabular}{|c|c|c|c|}
\hline \multirow[t]{2}{*}{ Covariates } & \multicolumn{3}{|c|}{ Old cohorts } \\
\hline & Coef. & Rel. risk & t-statistics \\
\hline \multicolumn{4}{|l|}{ Reference = Cohort 1949-1958 } \\
\hline $1959-1968$ & -0.481 & 0.618 & $-8.803^{* *}$ \\
\hline $1969-1973$ & -0.419 & 0.658 & -8.639 ** \\
\hline GDP per capita & -0.009 & 0.991 & -8.625 ** \\
\hline School enrolment & -3.703 & 0.025 & -13.302 ** \\
\hline \multicolumn{4}{|l|}{ Reference $=8$ th grade } \\
\hline Secondary education & -2.248 & 0.106 & -17.746 ** \\
\hline Professional/higher education & -4.807 & 0.008 & $-11.741^{* *}$ \\
\hline \multicolumn{4}{|l|}{ Reference = Having livestock } \\
\hline Do not have livestock & - & - & - \\
\hline \multicolumn{4}{|l|}{ Reference = Urban } \\
\hline Rural & 0.335 & 1.398 & 5.647 ** \\
\hline \multicolumn{4}{|l|}{ Reference $=$ Ger } \\
\hline Private house & -0.051 & 0.950 & -0.731 \\
\hline Apartment & -0.297 & 0.743 & $-4.189 * *$ \\
\hline Rural $x$ having livestock & - & - & - \\
\hline Rural x ger & 0.004 & 1.403 & 0.045 \\
\hline Number of births & 2960 & - & - \\
\hline -Log-likelihood & 14208 & - & - \\
\hline
\end{tabular}


Table 4: Maximum-likelihood estimates, first marriage

\begin{tabular}{|c|c|c|c|c|c|c|}
\hline \multirow[t]{2}{*}{ Covariates } & \multicolumn{3}{|c|}{ Old cohorts } & \multicolumn{3}{|c|}{ Young cohort } \\
\hline & Coef. & Rel. risk & t-statistics & Coef. & Rel. risk & t-statistics \\
\hline \multicolumn{7}{|l|}{ Reference = Cohort 1949-1958 } \\
\hline Cohort 1959-1968 & -0.313 & 0.731 & $-6.403^{* *}$ & - & - & - \\
\hline Cohort 1969-1973 & -0.254 & 0.776 & $-6.585^{* *}$ & - & - & - \\
\hline GDP per capita & 0.002 & 1.002 & $4.355 * \star$ & 0.006 & 1.006 & 3.512 ** \\
\hline School enrolment & -3.447 & 0.032 & $-22.889 * *$ & -2.949 & 0.052 & $-9.652 * *$ \\
\hline \multicolumn{7}{|l|}{ Reference $=8$ th grade } \\
\hline Secondary education & -0.007 & 0.993 & -0.185 & 0.321 & 1.379 & 4.056 ** \\
\hline $\begin{array}{l}\text { Professional/higher education } \\
\text { Reference = Have livestock }\end{array}$ & -0.502 & 0.605 & $-7.274^{* *}$ & - & - & - \\
\hline Do not have livestock & - & - & - & -0.005 & 0.995 & -0.040 \\
\hline \multicolumn{7}{|l|}{ Reference = Urban } \\
\hline Rural & 0.029 & 1.029 & 0.600 & 0.272 & 1.313 & 1.546 \\
\hline \multicolumn{7}{|l|}{ Reference $=$ Ger } \\
\hline Private house & 0.239 & 1.270 & 4.282 ** & 0.271 & 1.311 & 1.727 \\
\hline Apartment & 0.274 & 1.315 & $4.986^{* *}$ & 0.303 & 1.354 & 1.974 * \\
\hline Rural $x$ having livestock & - & - & - & 0.105 & 1.111 & -0.801 \\
\hline Rural x ger & 0.098 & 1.103 & 0.972 & 0.918 & 2.504 & $3.280 * *$ \\
\hline Number of births & 4723 & - & - & 886 & - & - \\
\hline -Log-likelihood & 22512 & - & - & 4784.4 & - & - \\
\hline
\end{tabular}




\section{References}

Alexandre Avdeev. 2001. "The extent of the fertility decline in Russia: is the onechild family here to stay?". IUSSP Seminar on International Perspectives on low Fertility: trends, theories and policies. National Institute for Population and Social Security Research. Tokyo. 21-23 March.

Government of Mongolia and UNDP. 2000. Human Development Report: Mongolia 2000. Ulaanbaatar: Admon Co.Ltd.

Government of Mongolia. 1993. Report on Population and Development.

Ulaanbaatar: Mongolia State Printing Company.

Blossfeld, Hans-Peter and Goetz Rohwer. 1995. Techniques of Event History

Modeling: New Approaches to Causal Analysis. New Jersey:

Lawrence Erlbaum Associates.

Kohler, Hans-Peter and Iliana Kohler. 2001. "Fertility Decline in Russia after 1990:

The role of Economic Uncertainty and Labor Market Crises”. MPIDR

Working paper 2001-013.

Morgan, Phil S. and Ronald R. Rindfuss. 1999. "Reexamining the Link of Early

Childbearing to Marriage and to Subsequent Fertility”. Demography. 36:59-75

National Statistical Office of Mongolia. 2000. Mongolian Statistical Yearbook.

Ulaanbaatar: Printing Company of the National Statistical Office of Mongolia.

National Statistical Office of Mongolia. 2000. Mongolia: 2000 Population and

Housing Census (preliminary results). Ulaanbaatar: Admon Co.Ltd.

National Statistical Office of Mongolia. 1999. Mongolia: Reproductive Health

Survey 1998. National Report. Ulaanbaatar: Admon Co.Ltd. 
National Statistical Office of Mongolia. 1994. Population of Mongolia. Ulaanbaatar: Mongolian State Printing Company.

National Statistical Office of Mongolia. 1995. Women and Children of Mongolia.

Ulaanbaatar: Printing Company of the National Statistical Office of Mongolia.

Neupert, Ricardo F. 1996. Population Policies, Socioeconomic Development and

Population Dynamics in Mongolia. Canberra: National Capital Printing.

Research School of Social Sciences. Australian National University.

Zakharov, Sergei V. and Elena. I. Ivanova. 1996. "Fertility Decline and Recent

Changes in Russia: On the Threshold of the Second Demographic Transition. In

Russia’s Demographic "Crisis". Eds. Julie S. Davanzo and Gwen Farnsworth.

Rand Documents. p: XVIII, 205.

Kharkova, Tatiana L. and E. M. Andreev. 2000. "Did the Economic Crisis Cause the Fertility Decline in Russia: Evidence from the 1994 Microcensus.” European Journal of Population. 16:211-233.

Van de Kaa, Dirk J. 1987. “Europe's Second Demographic Transition”, Population Bulletin. 42:1-55.

\section{Acknowledgements}

We would like to thank participants at the EAPS2001 conference in Helsinki, Jan Hoem and Francesco Billari for their useful comments. The authors are responsible for any remaining errors. 